\title{
The Effect of a Cognitive-Behavioral Intervention on Diet and Exercise Among Asian Americans and Pacific Islanders With Type 2 Diabetes
}

Asian / Pacific Island Nursing Journal April-June 2015: 1-11 (C) The Author(s) 2015 DOI: $10.1177 / 2373665815581368$ apn.sagepub.com (SAGE

\author{
Jan Yomogida ${ }^{1}$, Jillian Inouye ${ }^{2}$, Dongmei $\mathrm{Li}^{3}$, and James Davis ${ }^{4}$
}

\begin{abstract}
Type 2 diabetes accounts for $90 \%$ to $95 \%$ of all diabetic cases with Asian Americans and Pacific Islanders particularly at risk. The purpose was to assess the effects of a cognitive-behavioral intervention (CBI) on diet and exercise among Asian Americans and Pacific Islanders with type 2 diabetes. Using a double-blinded, two-arm randomized clinical trial $(n=207)$, data on diet and exercise were analyzed before and after a 6-week CBI. Over time, treatment group showed a decrease in kcals and increase in steps compared with control group; however, results were not statistically significant. Treatment group had lower kcals of trans-fat, saturated fat, sugar, alcohol, caffeine, and dietary fiber compared with the control group. Older subjects and females had significantly lower caloric intake $(p<.01)$. Females exercised less and took fewer steps compared with males $(p<.05)$. CBI may be effective in lowering calorie intake and increasing physical activity among Asian Americans and Pacific Islanders with type 2 diabetes. Significant differences in gender and age point to the need for individualized research and treatment targeting this group.
\end{abstract}

\section{Keywords}

cognitive-behavioral intervention, CBT, type 2 diabetes, Asian Americans and Pacific Islanders, self-management, diet and exercise

Type 2 diabetes is a growing epidemic and those particularly at risk are ethnic minorities including Pacific Islanders and Asian Americans (Centers for Disease Control and Prevention [CDC], 2013; National Institute of Diabetes and Digestive and Kidney Diseases, 2014; The Office of Minority Health, 2014). In Hawai'i, $~ 80,000$ adults (7.8\% of the population) are diagnosed with diabetes (Hawai' $i$ Health Data Warehouse, Hawai'i State Department of Health, \& Behavioral Risk Factor Surveillance System, 2014) and an estimated 26,000 remain undiagnosed (Pobutsky, Balabis, Nguyen, \& Tottori, 2010). The CDC (2011) reported that Asians and Pacific Islanders including Native Hawaiians have at least twice the prevalence of type 2 diabetes than Caucasians (The Office of Minority Health, 2014).

Previous research indicated cognitive-behavioral therapy (CBT) to be effective among people with diabetes (Christie \& Wilson, 2005; Foreyt \& Poston, 1999; Gonzalez et al., 2010; Lustman, Griffith, Freedland, Kissel, \& Clouse, 1998; Markowitz, Carper, Gonzalez, Delahanty, \& Safren, 2012; Safren et al., 2014; Snoek \& Skinner, 2002; Surwit et al., 2002) and among Asian Americans and Pacific Islanders (Chen \& Davenport, 2005; Dai et al., 1999; Voss Horrell, 2008; Williams, Foo, \& Haarhoff, 2006; Wong, Chau, Kwok,
\& Kwan, 2007), yet until now, no study has examined CBT's effectiveness among Asian Americans and Pacific Islanders with type 2 diabetes.

To address effectiveness of CBT, the ENHANCE Project (Inouye, 2005), double-blinded, two-arm randomized clinical trial, was conducted with 207 Asian American and Pacific Islander adults with type 2 diabetes to measure behavioral change related to diabetes management. Because results on biological outcomes were reported elsewhere, the specific aim of the present study utilizing data from the ENHANCE Project was to assess whether the cognitive-behavioral intervention (CBI) was effective in improving dietary and exercise behaviors among Asian Americans and Pacific Islanders with type 2 diabetes. It was hypothesized that CBI would

\footnotetext{
${ }^{1}$ Western Psychological and Counseling Services, Portland, OR, USA ${ }^{2}$ University of Nevada, Las Vegas, USA

${ }^{3}$ University of Rochester Medical Center, New York, USA

${ }^{4}$ University of Hawai'i, Honolulu, USA

\section{Corresponding Author:}

Jillian Inouye, School of Nursing University of Nevada, 4505 S. Maryland Parkway, Las Vegas, NV 89154-3018, USA.

Email: Jillian.inouye@unlv.edu
} 
Table 1. Demographics of Participants.

\begin{tabular}{|c|c|c|c|c|}
\hline Variable & $\begin{array}{l}\text { CBI group } \\
(n=104)\end{array}$ & $\begin{array}{l}\text { Control group } \\
\quad(n=103)\end{array}$ & $n$ & $p$ value $^{\mathrm{a}}$ \\
\hline Race/ethnicity ( $n=207)$ & & & & .6356 \\
\hline Asian American & $65(63.72 \%)$ & $68(68.00 \%)$ & $133(65.84 \%)$ & \\
\hline Chinese & $10(9.80 \%)$ & 10 (10.00\%) & 20 (9.90\%) & \\
\hline Japanese & $42(41.18 \%)$ & 34 (34.00\%) & $76(37.62 \%)$ & \\
\hline Filipino & $11(10.78 \%)$ & $18(18.00 \%)$ & $29(14.36 \%)$ & \\
\hline Korean & $2(1.96 \%)$ & $4(4.00 \%)$ & $6(2.97 \%)$ & \\
\hline South East Asian & $1(0.98 \%)$ & $2(2.00 \%)$ & $3(1.49 \%)$ & \\
\hline Pacific Islanders & $30(29.41 \%)$ & 27 (27.00\%) & $57(28.22 \%)$ & \\
\hline Part Native-Hawaiian & 27 (26.47\%) & $26(26.00 \%)$ & $53(26.24 \%)$ & \\
\hline Pacific Islander & $3(2.94 \%)$ & $1(1.00 \%)$ & $4(1.98 \%)$ & \\
\hline Mixed & $4(3.92 \%)$ & $5(5.00 \%)$ & $9(4.46 \%)$ & \\
\hline Other & $2(1.96 \%)$ & $0(0.00 \%)$ & $2(0.99 \%)$ & \\
\hline Age $(n=207)$ & & & & .8249 \\
\hline 18- to 29-year-old Asians, $M=59$ years & $2(1.98 \%)$ & $3(3.00 \%)$ & $5(2.49 \%)$ & \\
\hline 30- to 39-year-olds & $5(4.95 \%)$ & $3(3.00 \%)$ & $8(3.89 \%)$ & \\
\hline $\begin{array}{l}\text { 40- to } 49 \text {-year-old Pacific Islanders, } \\
M=55 \text { years }\end{array}$ & $19(18.81 \%)$ & $15(15.00 \%)$ & $34(16.92 \%)$ & \\
\hline 50- to 59-year-olds & $24(23.76 \%)$ & $29(29.00 \%)$ & $53(26.37 \%)$ & \\
\hline 60- to 69-year-olds & $42(41.58 \%)$ & $38(38.00 \%)$ & $80(39.80 \%)$ & \\
\hline 70- to 79-year-olds & 9 (8.91\%) & $12(12.00 \%)$ & $21(10.45 \%)$ & \\
\hline$>80$-year-olds & $0(0.00 \%)$ & $0(0.00 \%)$ & $0(0.00 \%)$ & \\
\hline Gender $(n=207)$ & & & & .5341 \\
\hline Male & $45(43.27 \%)$ & 49 (47.57\%) & $94(45 \%)$ & \\
\hline Female & $59(56.73 \%)$ & $54(52.43 \%)$ & $113(55 \%)$ & \\
\hline Education level ( $n=207$ ) & & & & .3737 \\
\hline Less than high school education & $11(11.00 \%)$ & $8(8.00 \%)$ & $19(9.50 \%)$ & \\
\hline High school graduate & $10(10.00 \%)$ & $12(12.00 \%)$ & $22(11.00 \%)$ & \\
\hline Some college education & $29(29.00 \%)$ & 37 (37.00\%) & $66(33.00 \%)$ & \\
\hline College graduate & $33(33.00 \%)$ & $22(22.00 \%)$ & $55(27.50 \%)$ & \\
\hline Graduate school graduate & 17 (17.00\%) & $21(21.00 \%)$ & 38 (19.00\%) & \\
\hline
\end{tabular}

Note. $\mathrm{CBI}=$ cognitive-behavioral intervention.

${ }^{a} p$ values are from either $\chi^{2}$ tests or Fisher's exact tests.

improve behavioral patterns of diet and exercise among this group.

\section{Method}

\section{Participants}

Out of a potential pool of 1,891 participants, 631 participants were selected for inclusion. Of those, 424 were not eligible, not interested, and/or unable to schedule a time to complete the interview, sign the consent form, or complete the pre-test of the diabetes knowledge scale. After the screening, 207 eligible people agreed to participate in this study and were randomized by the statistician to the treatment $(n=104)$ or control group $(n=103)$. See Table 1 for demographics of participants chart.

Inclusion/exclusion criteria. Participants included those who were diagnosed with type 2 diabetes by a physician and met diagnostic criteria established by the American Diabetes Association (2012). They were also included if they reported being of Asian American or Pacific Islander descent. Participants were excluded if they were symptomatic of hyperglycemia, presented with physical conditions that inhibited their participation in an exercise regimen, had physical or cognitive difficulties that interfered with their participation in group processing, or at any time of the study, were likely to become inaccessible (i.e., considered changing of residency).

Participants who met criteria for this study were recruited upon completion of a three-visit session of diabetes educa- tion classes at the Specialty Clinic affiliated with The Division of Endocrinology and Metabolism of the University of Hawai'i School of Medicine. Monetary and other incentives (i.e., lunch bags, water bottles, and pedometers) were given at the outset and follow-up intervals.

Protection of participants. This study was approved by the University of Hawai'i's Institutional Review Board (CHS 
17509). Ethical considerations including safety, confidentiality, and security of records were taken into account. All participants signed an informed consent form that included a description of the study and their rights and responsibilities. They were informed that their participation was voluntary and could be stopped at any time. To ensure their safety and well-being, group facilitators were trained to assess signs of distress and were instructed to contact the principal investigator or co-investigators immediately if participants became significantly stressed, depressed, or agitated during any time of the study, so that further action could be taken (i.e., refer to counseling). Confidentiality was protected using coded numbers for each participant and data excluded any identifiable information. Data were stored in a locked file cabinet accessible only by The ENHANCE Project's program manager, and inputted into a password protected computer by selected student volunteers who were trained in maintaining and protecting the confidentiality of the data.

Power analysis and sample size. Estimated treatment effects used the following sample size formula: $N=[2 \times(Z \alpha$ $\left./ 2+Z \beta)^{2} \times \sigma^{2}\right] / \delta^{2} . N$ represents the sample size per group; $Z \alpha / 2$ and $Z \beta$ represents the standard normal deviates for type I and type II errors, $\sigma^{2}$ represents the squared standard deviation, and $\delta^{2}$ represents the squared difference between the treat- ment and control groups. Effect sizes were calculated on the assumptions that there would be a 5\% type I error and 20\% type II error, providing a power of $80 \%$. Published effects from research on behavioral interventions estimated that the treatment group would have $\geq 15 \%$ greater adherence to self- management behaviors than the control group (Méndez \& Beléndez, 1997), and a 10\% to $30 \%$ improvement for other dependent variables (Grey et al., 1998; Inouye, Flannelly, \& Flannelly, 2001; Méndez \& Beléndez, 1997). Treatment effects (delta), calculated based on published means and standard deviations as well as upon the 164 participants ( 82 per group) predicted to complete the trial (Bielamowicz, Miller, Elkins, \& Ladewig, 1995), estimated a $\geq 7.9 \%$ change from baseline for the diabetes selfmanagement record (DSMR). For dietary fat and exercise, treatment effects were detected at $15 \%$ to $21 \%$ and $34 \%$ to $40 \%$, respectively. Based on these estimated treatment effects, the power analysis showed a total sample size of 207, which is large enough to have at least $80 \%$ power.

\section{Measures}

Diet and exercise were assessed using the DSMR, a selfmonitoring record designed to monitor daily nutritional intake, physical activity, and glucose monitoring (Bielamowicz et al., 1995). The diet portion of the DSMR included a 3-day, 24-hr diet record listing the type, portion size, and preparation style of all foods consumed. The 24-hr diet recall has been shown to be a valid (Beer-Borst \& Amado, 1995; Chernoff, 2003; Schroder et al., 2001) and reliable (Sun, Roth, Ritchie, Burgio, \& Locher, 2010) method for estimating dietary intake. The $24-\mathrm{hr}$ food recall allows participants to record unique dietary patterns and culturally specific food preferences. Unlike other nutritional assessments measuring food intake (i.e., the Food Frequency Questionnaire), the 24-hr diet recall is often used because it does not rely so heavily upon memory, thus more accurately portraying typical eating patterns. Participants were verbally informed on how to complete the diet records and given written examples on how to record their daily consumption. As suggested by research (Chernoff, 2003), participants were encouraged to record their nutritional intake for 2 weekdays and at least 1 weekend day for greater generalizability of usual eating patterns. This was collected at three time points. Dietary intake was analyzed using the Nutritionist Pro 4.0 software.

Physical activity was measured by a pedometer and documented on the bottom portion of the DSMR. Pedometers were shown to be a useful tool in objectively measuring the number of steps achieved in a day and for tracking physical activity in clinical populations (Bassett \& John, 2010; Furber et al., 2008). Participants were instructed to measure activity for 1 week before data collection.

\section{Procedure}

Group assignment/description of groups. Using a table of ran- dom numbers, participants were randomized into the control or treatment group via sealed, numbered envelopes that con- tained the randomized assignment. Treatment and control groups were designed to meet $1.5-\mathrm{hr}$ per session and encour- aged to bring their spouse/partner to sessions. Sessions ranged from two to six participants, were held on consecu- tive weeks, and were scheduled according to the day/time participants were able to visit the site. The total number of sessions ( 6 weeks as opposed to 12 weeks in other studies) was based on cost-effectiveness of this study and the preven- tion of drop-out rates. Sessions were conducted by staff trained by the principal investigator and chosen based on their experience in research and/or diabetes self-manage- ment. The program coordinator or research assistants led the sessions and were supervised by a highly experienced researcher of diabetes-related clinical trials.

Each facilitator was provided with a set of guidelines to use for running each session. For the first session, the agenda involved a welcome message, introduction of the group facilitator, things participants could expect, and the personal rights/confidentiality of participants. Each subsequent session, guidelines included a brief review of the previous session, a brief orientation of the topic being discussed with goals and objectives, and specific protocols/step-by-step procedures for conducting the session.

The step-by-step procedures were developed by the principal investigator and manualized as an intervention (Inouye, 2004, 2005). The treatment manual included separate modules 
Asian/Pacific Island Nursing Journal, Vol. 1, Iss. 1 [2016], Art. 7

designed to be discussed at each session with a specific script for researchers to follow. Topics in the control group included a review of diabetes education and personal experiences associated with diabetes self-care (e.g., topics covered eye exams, insurance coverage, foot care, traveling with diabetes, dental care, and sick day management), whereas the intervention group included a comprehensive training on various cognitive-behavioral restructuring and coping tools.

Cognitive-behavioral methods are known to bring into awareness people's automatic thoughts, cognitive distortions (unrealistic beliefs about themselves, others, and events), and their personal reactions to adverse stimuli (BrooksHarris, 2008). It is also known to help individuals understand how their thoughts, feelings, and actions are interconnected. Elements of CBIs include setting realistic and specific goals, identifying barriers to change, problem solving, cognitive restructuring, and stress reduction (Beck, 1995; BrooksHarris, 2008; Goldfried \& Davison, 1994).

The CBI used in the current study involved psychoeducation and group discussion around factors influencing diabetes management such as self-belief, cognitive distortions, restructuring of thoughts, stress management, and coping tools to achieve and maintain positive changes. Topics in the cognitive-behavioral group included "Self-efficacy" (Session 1); "Cognitive Restructuring and Management of Internal and Distorted Thoughts" (Session 2); "Stress Theory, Mood Control and Management" (Session 3); "Relaxation" (Session 4); "Time Management and Values Clarification" (Session 5); and "Change Strategies and Relapse Prevention" (Session 6). Each session in the CBI group included a series of goals, strategies, and homework assignments. See Table 2 for the schedule of sessions.

Overall rigor/integrity of study. The study's rigor was demon- strated through the consistency of training at sessions among both groups, selection of sample population, and effort in minimizing research biases. To avoid subject contamination (i.e., communication between the control and intervention groups), sessions were held on different dates/times (Inouye, 2005). To maintain integrity and consistency of the training sessions among group facilitators, investigators of the pro- gram informed facilitators that they would be observing ses- sions at any given time without advanced notice. This ensured that the protocols were being followed by each trainer. To increase validity of the sessions, manipulation checks were performed and found no significant differences in participants' satisfaction with group facilitators. In an effort to minimize bias, the study and participants' outcomes were blinded to the facilitators and assistants who provided the interventions. Outcomes were also blinded to those who conducted the data entry and analyses.

Volunteers recruited to assist in the data entry were selected based on their knowledge in nutrition and computer application skills. Validity checks were conducted on at least one third of the data entered. Volunteers who assisted in the data
Table 2. Schedule of Sessions for Control and CBI group.

\begin{tabular}{|c|c|c|c|}
\hline Group & Session & Week & Lesson/activity \\
\hline \multirow[t]{6}{*}{$\begin{array}{l}\text { Control } \\
\text { group }\end{array}$} & 1 & 1 & $\begin{array}{l}\text { Welcome, introduction, } \\
\text { orientation, eye examinations, } \\
\text { baseline test of self-management } \\
\text { knowledge }\end{array}$ \\
\hline & 2 & 2 & Insurance coverage \\
\hline & 3 & 3 & Foot care \\
\hline & 4 & 4 & Traveling with diabetes \\
\hline & 5 & 5 & Dental care \\
\hline & 6 & 6 & Sick day management \\
\hline \multirow[t]{6}{*}{$\mathrm{CBI}$ group } & 1 & 1 & $\begin{array}{l}\text { Welcome, introduction, } \\
\text { orientation, self-management, } \\
\text { personal setting of goals, } \\
\text { baseline test of self-management } \\
\text { knowledge }\end{array}$ \\
\hline & 2 & 2 & $\begin{array}{l}\text { Cognitive restructuring, affect } \\
\text { management, and management } \\
\text { of cognitive distortions }\end{array}$ \\
\hline & 3 & 3 & Stress theory and management \\
\hline & 4 & 4 & Stress and relaxation \\
\hline & 5 & 5 & Cultural influences on behaviors \\
\hline & 6 & 6 & $\begin{array}{l}\text { Time management, exitinterview, } \\
\text { post-treatment questionnaire }\end{array}$ \\
\hline
\end{tabular}

Note. $\mathrm{CBI}=$ cognitive-behavioral intervention.

entry of food records were recruited from the University via flyers where nutrition and food science classes were held. All volunteers were upper-level students majoring in nutrition and were experienced with nutritional software data entry. Although the students had experience in data entry, they underwent a group training on the Nutritionist Pro provided by the project's research dietitian to ensure consistency and accuracy of the data input. Due to the wide variability in the DSMRs, as expected with self-reported dietary and exercise records, volunteers were asked to estimate ambiguous food items or unreported portion sizes based on previous consumption patterns and/or use the software's default standard sizes for consistency among data entry. Although the Nutritionist Pro software consists of over 35,000 different foods including foods unique to Hawai'i (Axxya Systems LLC, Redmond, WA), certain cultural foods were absent from the database. Thus, ingredients of specific foods were searched online and inputted individually. To further enhance consistency and accuracy of the data, validity checks were performed on at least one third of the data by the registered dietitian.

\section{Analyses}

Statistical analyses of variables within/across groups. Diet was analyzed using a 2 (two levels of treatment) $\times 3$ (baseline vs. post-test vs. 12-month follow-up) Wilcoxon analysis to account for the vast discrepancy of the data among participants. Due to the stability among the exercise data, a linear regression model 
was utilized to evaluate exercise levels. The Wilcoxon analysis assessed the differences in medians, whereas the linear regression model assessed the differences in means.

Both nutrient and exercise analyses were further conducted using linear mixed-effect models to examine the differences between the treatment and the control group after adjusting potential confounding factors such as age, gender, and ethnicity in the model. The linear mixedeffect models took the within-subject correlations from multiple time points into account and thus have higher power than the linear regression models. The residual diagnoses were conducted to check the normality assumption of the linear mixed-effect models and the normality assumptions are all met. No outliers or influential data points were identified from the data set. All statistical analyses were conducted using the SAS 9.3 statistical analysis software (SAS Institute, Cary, NC) and the significance level was set at $5 \%$.

\section{Results}

\section{Baseline Differences of General Characteristics Between Treatment and Control Groups}

There were no significant differences between the two groups in demographic characteristics of age, gender, marital status, and education as shown in Table 1.

\section{Baseline Calorie Intake and Exercise Levels Established for Ancestry, Gender, and Age}

At baseline, cross-sectional analyses evaluated the associations of calorie intake and exercise levels among ancestry, gender, and age. Participants of Pacific Island ancestry had a lower total calorie intake $(1,535 \mathrm{kcals})$ than those of Asian descent $(1,588 \mathrm{kcals})$. Although these findings did not reach statistical significance, exercise levels were significantly lower in Pacific Islanders (4,089 steps) than in Asian Americans (5,337 steps, $p<.05)$. Regarding gender, females had a lower total calorie intake $(1,558 \mathrm{kcals})$ than males $(1,662 \mathrm{kcals})$, as well as a lower estimated exercise level (4,768 steps) than males (5,423 steps, see Table 3$)$. Furthermore, as age increased, total calorie intake and exercise levels decreased.

\section{Results of CBT Treatment on Caloric Intake}

Cross-sectional analyses using the Wilcoxon's test revealed that at baseline, the total daily calories for the treatment group $(n=76)$ was $1,681 \mathrm{kcals}$ and $1,538 \mathrm{kcals}$ for the control group ( $n=82$, see Table 3$)$. At post-test, the consumption for the treatment $(n=50)$ and control groups $(n=65)$ were 1,658 and 1,641 kcals, respectively. The 1-year follow-up assessment revealed that the treatment group $(n=$ 42) consumed 1,582 kcals/day, whereas the control group $(n=53)$ consumed $1,641 \mathrm{kcals} / \mathrm{day}$. Although treatment effects were not strong enough to show statistical significance, the intervention group showed slight improvement in self-management. A decrease in the median number of calories at each time interval was observed in the treatment group (1,681 at pre-test, 1,658 at post-test, and 1,582 kcals at 1 year). In contrast, the control group showed a slight increase in caloric intake (1,538 at pre-test, 1,641 at posttest, and 1,641 kcals at 1 year). In addition, a comparison of the group average of within-individual differences showed that at the end of 1 year, the treatment group consumed 138 kcals less $(18-156=-138 \mathrm{kcals})$ than the control group. Despite smaller than expected changes, these results infer that CBT may provide beneficial outcomes in dietary management (see Table 4).

Based on linear mixed-effect models, the treatment and control groups showed statistically significant differences in the average daily consumption of trans-fat, saturated fat, sugar, and alcohol post-adjustment of age, gender, and ethnicity (see Table 5). Trans-fat consumption in the treatment group decreased by $26 \mathrm{kcals} /$ day from the time period of Week 6 to 1 year, whereas it increased by $42 \mathrm{kcals} /$ day in the control group $(p<.001)$. Similarly, saturated fat consumption in the treatment group was significantly reduced by 32 kcals/day from Week 6 to 1 year whereas the control group increased their saturated fat intake by $102 \mathrm{kcals} /$ day $(p<$ .001). Within the same time period, the treatment group had significant reduction in intake of sugar $(p<.05)$, alcohol $(p<.001)$, and caffeine $(p<.001)$. Dietary fiber consumption from baseline to 6 weeks was additionally significantly reduced $(p=.049)$.

Regarding age, older participants consumed less total calories/day compared with younger participants $(p<.05)$ Females consumed 207 less calories/day than males ( $p<$ .001) indicating a significant difference in total intake.

\section{Results of CBT Treatment on Exercise}

Different from the dietary analysis, exercise did not yield statistically significant results. At baseline, the treatment group ( $n=76)$ averaged 4,721 steps/day compared with the control group $(n=86)$ at 5,355 steps/day (see Table 3). Post-test results showed that both groups increased in their number of steps. The mean number of steps in the treatment group $(n=$ 58) was 4,927 and 5,809 in the control group $(n=72)$. At 1 year follow-up, the change in both groups was not sustained. The treatment group $(n=53)$ exerted 4,843 steps and the control group $(n=63), 4,975$ steps.

Despite the lack of statistical power, the treatment group showed an overall improvement of exercise behaviors at the end of 1 year. Group comparisons of within-individual differences showed that the treatment group increased their total number of steps/day by 563 , whereas the control group declined by 211 steps/day (see Table 4 ). This further suggests that CBI may have a positive impact on diabetes self-management. 
Asian/Pacific Island Nursing Journal, Vol. 1, Iss. 1 [2016], Art. 7

Table 3. Comparisons of Total Calories and Steps Regarding Treatment Group, Ancestry, and Gender at Baseline.

\begin{tabular}{|c|c|c|c|c|c|c|c|c|c|}
\hline & \multirow{2}{*}{$\frac{\text { Diet }}{n}$} & \multicolumn{8}{|c|}{ Exercise } \\
\hline & & $\begin{array}{l}\text { Total } \\
\text { kcals }\end{array}$ & $\begin{array}{l}\text { Lower } \\
\text { quartile }\end{array}$ & $\begin{array}{l}\text { Upper } \\
\text { quartile }\end{array}$ & $\begin{array}{c}p \\
\text { value }\end{array}$ & $n$ & $\begin{array}{l}\text { Total } \\
\text { steps }\end{array}$ & $S D$ & $\begin{array}{c}p \\
\text { value }\end{array}$ \\
\hline \multicolumn{10}{|l|}{ Group } \\
\hline Treatment & 76 & 1,681 & 1,315 & 1,926 & .13 & 76 & 4,721 & 2,812 & .32 \\
\hline Control & 82 & 1,538 & 1,259 & 1,918 & & 86 & 5,355 & 3,371 & \\
\hline \multicolumn{10}{|l|}{ Ancestry } \\
\hline Asian & 114 & 1,588 & 1,309 & 1,933 & .93 & 106 & 5,337 & 3,265 & $.04^{*}$ \\
\hline Pacific Islander & 35 & 1,535 & 1,188 & 1,928 & & 30 & 4,089 & 2,573 & \\
\hline \multicolumn{10}{|l|}{ Gender } \\
\hline Male & 69 & 1,662 & 1,326 & 2,010 & .14 & 61 & 5,423 & 3,364 & .14 \\
\hline Female & 80 & 1,558 & 1,224 & 1,897 & & 75 & 4,768 & 2,974 & \\
\hline
\end{tabular}

Note. Amount of total daily calories and total number of steps based on an average of 3-day diet records at baseline. The results are age-adjusted. $* p<.05$

Table 4. Statistical Significance of the Changes in Diet and Exercise Between Treatment and Control Groups at 6 Weeks and 1-Year Follow-Up Exams.

\begin{tabular}{|c|c|c|c|c|c|c|c|c|c|}
\hline \multirow[b]{2}{*}{ Time frame } & \multicolumn{5}{|c|}{ Diet } & \multicolumn{4}{|c|}{ Exercise } \\
\hline & $n$ & $\begin{array}{c}\text { Kcal } \\
\text { differences }\end{array}$ & $\begin{array}{l}\text { Lower } \\
\text { quartile }\end{array}$ & $\begin{array}{l}\text { Upper } \\
\text { quartile }\end{array}$ & $p$ value & $n$ & $\begin{array}{l}\text { Differences in } \\
\text { no. of steps }\end{array}$ & $S D$ & $p$ value \\
\hline \multicolumn{10}{|l|}{6 weeks } \\
\hline Treatment & 50 & 41 & -395 & 371 & .84 & 45 & -57 & 3,509 & .53 \\
\hline Control & 65 & -37 & -317 & 252 & & 52 & 451 & 4,361 & \\
\hline \multicolumn{10}{|l|}{1 year } \\
\hline Treatment & 42 & 18 & -288 & 320 & .15 & 37 & 563 & 4,081 & .50 \\
\hline Control & 53 & 156 & -162 & 432 & & 44 & -211 & 5,908 & \\
\hline
\end{tabular}

Note. Amount of kilocalories and exercise differences based on an average of individual differences per group at follow-up exams; $p$ values based on group differences at follow-up exams.

\section{Discussion}

The lack of statistical significance for specific expected outcomes may be due to several factors. First, results may have been influenced by the short duration of the CBI treatment and the insufficient time for the cognitive-behavioral skills to be learned and applied to everyday life. Previous studies have shown that CBT was effective in improving treatment outcomes in 12 sessions (Cucciare, Sorrell, \& Trafton, 2009; Gelman, López, \& Foster, 2005; Gonzalez et al., 2010; Hinton et al., 2005; Organista, Muñoz, \& González, 1994). Given that this study provided CBT over just 6 sessions and that other studies showed efficacy with CBT conducted over 12 sessions, results might suggest that the intervention may not have been long enough. As mentioned earlier, a 6-week intervention period was chosen based on the cost-effectiveness of this study and to prevent drop-out rates. Despite the lack of statistical significance, it is worthy to note that the treatment group showed an improvement in both diet and exercise over time than the control group. This might imply that CBT, to some extent, may show promise in facilitating participants toward adherence in self-care behaviors.
Another factor that may have contributed to these findings is the high variability in calories and steps recorded. Maintaining a thorough and accurate log may have been influenced by participants' business in daily schedules, malfunctioning of pedometer, forgetfulness, or tiredness. The high disparity in the recording of total kcal intake and physical activity made it unfeasible to draw firm conclusions. Regarding the use of 24-hr diet records, several studies question its validity and suggest that this measurement is prone to over- or underestimating intakes (Hoidrup et al., 2002; Madden, Goodman, \& Guthrie, 1976; Poslusna, Ruprich, de Vries, Jakubikova, \& van't Veer, 2009). With analyses of dietary intake (Beaton, 1994; Jackson, Byrne, Magarey, \& Hills, 2008; Sawaya et al., 1996) and physical activity (Lee, Whittemore, \& Lung, 1992) among large groups of people, random error (day-to-day variability in food intake) is known to be inevitable; therefore, some researchers recommend recording dietary intake for 7 to 8 days to truly represent a typical eating pattern (Chernoff, 2003; Jackson et al., 2008). Although this study was originally designed to collect food intake over 7 days, it was reduced to 3 days because participants found it difficult to complete their diet recall for the 
Table 5. Statistical Significance of the Changes Over Time in Trans-Fat, Sugar, Alcohol, Caffeine, Diet Fiber, and Saturated Fat Consumption Between Treatment and Control Groups.

\begin{tabular}{|c|c|c|c|c|c|c|}
\hline & \multicolumn{3}{|c|}{ Baseline } & & \multirow[b]{2}{*}{$p$ value for trend ${ }^{a}$} & \\
\hline & Week 1 & Week 6 & 1 year & & & \\
\hline \multicolumn{7}{|l|}{ Trans-fat } \\
\hline Treatment & $7.57 \pm 7.69$ & $26.66 \pm 8.86$ & $1.15 \pm 9.27$ & & .601 & \\
\hline Control & $24.16 \pm 7.48$ & $7.06 \pm 7.85$ & $48.63 \pm 8.50$ & & .035 & \\
\hline \multicolumn{7}{|l|}{ Sugar } \\
\hline Treatment & $58.13 \pm 5.86$ & $65.57 \pm 6.72$ & $58.20 \pm 7.03$ & & .993 & \\
\hline Control & $59.55 \pm 5.76$ & $55.77 \pm 5.98$ & $74.21 \pm 6.41$ & & .065 & \\
\hline \multicolumn{7}{|l|}{ Alcohol } \\
\hline Treatment & $0.67 \pm 0.83$ & $2.58 \pm 0.95$ & $1.11 \pm 0.99$ & & .711 & \\
\hline Control & $3.29 \pm 0.82$ & $1.25 \pm 0.85$ & $5.54 \pm 0.91$ & & .041 & \\
\hline \multicolumn{7}{|l|}{ Caffeine } \\
\hline Treatment & $125.22 \pm 20.10$ & $159.25 \pm 22.96$ & $126.78 \pm 23.98$ & & .955 & \\
\hline Control & $133.57 \pm 19.82$ & $112.83 \pm 20.49$ & $214.73 \pm 21.86$ & & .002 & \\
\hline \multicolumn{7}{|l|}{ Diet fiber } \\
\hline Treatment & $14.28 \pm 0.79$ & $17.61 \pm 0.90$ & $16.54 \pm 0.94$ & & .039 & \\
\hline Control & $13.06 \pm 0.78$ & $13.58 \pm 0.80$ & $13.93 \pm 0.86$ & & .386 & \\
\hline \multicolumn{7}{|l|}{ Saturated fat } \\
\hline Treatment & $24.86 \pm 7.60$ & $40.82 \pm 8.76$ & $20.14 \pm 9.17$ & & .687 & \\
\hline \multirow[t]{2}{*}{ Control } & $31.10 \pm 7.42$ & $25.49 \pm 7.76$ & $64.04 \pm 8.37$ & & .003 & \\
\hline & $\begin{array}{c}\Delta \text { baseline to } \\
\text { Week } 6\end{array}$ & $p$ value $^{\mathrm{b}}$ & $\begin{array}{c}\Delta \text { Week } 6 \text { to } 1 \\
\text { year }\end{array}$ & $p$ value $^{\mathrm{b}}$ & $\begin{array}{c}\Delta \text { baseline to } \\
1 \text { year }\end{array}$ & $p$ \\
\hline Trans-fat & & .027 & & .000 & & .068 \\
\hline Treatment & $19.10 \pm 11.97$ & & $-25.51 \pm 13.07$ & & $-6.42 \pm 12.27$ & \\
\hline Control & $-17.10 \pm 11.10$ & & $41.57 \pm 11.81$ & & $24.47 \pm 11.55$ & \\
\hline Sugar & & .315 & & .033 & & .209 \\
\hline Treatment & $7.44 \pm 8.19$ & & $-7.36 \pm 9.01$ & & $0.07 \pm 8.48$ & \\
\hline Control & $-3.78 \pm 7.56$ & & $18.44 \pm 8.03$ & & $14.66 \pm 7.91$ & \\
\hline Alcohol & & .011 & & .001 & & .261 \\
\hline Treatment & $1.91 \pm 1.14$ & & $-1.47 \pm 1.25$ & & $0.44 \pm 1.18$ & \\
\hline Control & $-2.04 \pm 1.05$ & & $4.29 \pm 1.11$ & & $2.25 \pm 1.10$ & \\
\hline Caffeine & & .135 & & .001 & & .038 \\
\hline Treatment & $34.04 \pm 26.87$ & & $-32.47 \pm 29.62$ & & $1.57 \pm 27.90$ & \\
\hline Control & $-20.75 \pm 24.72$ & & $101.91 \pm 26.27$ & & $81.16 \pm 25.94$ & \\
\hline Diet fiber & & .049 & & .354 & & .353 \\
\hline Treatment & $3.33 \pm 1.05$ & & $-1.07 \pm 1.15$ & & $2.26 \pm 1.09$ & \\
\hline Control & $0.52 \pm 0.96$ & & $0.36 \pm 1.02$ & & $0.88 \pm 1.01$ & \\
\hline Saturated fat & .165 & & .001 & & .020 & \\
\hline Treatment & $34.04 \pm 26.87$ & & $-32.47 \pm 29.62$ & & $1.57 \pm 27.90$ & \\
\hline Control & $-20.75 \pm 24.72$ & & $101.91 \pm 26.27$ & & $81.16 \pm 25.94$ & \\
\hline
\end{tabular}

${ }^{\mathrm{a}} p$ value for within treatment/control group changes from baseline to 1 year.

${ }^{\mathrm{b}} p$ value for comparing the changes between the treatment group and the control group.

full 7 days. Hence, the wide variability among our dietary data could have been attributed to the insufficient number of days needed to minimize the effects of random error.

An additional factor that may have influenced results is motivation. When people are not ready to change, treatment has been shown to be ineffective (Hart \& Hart, 2010; Prochaska, Norcross, \& DiClemente, 1994). As motivation level was not assessed, it may be that participants were not motivated or receptive to the treatment in the first place. The design of the control group may have also accounted for the lack of statistical significance in the results. As the control group included social support and additional education involving a series of goals, strategies, and homework assignments, the control group might be considered another treatment group rather than an actual control group. With the attention-control group receiving more than the usual care, 
between-group differences may have been smaller than one would expect with a standard control group. Lastly, the sample size of the study may have been too small to yield statistical significance of our findings. Due to the high variability among data involving diet and exercise, a larger sample size may be needed to reflect true change.

\section{Other Limitations}

Due to the high variability among the data, these findings are not generalizable. The use of self-reported measures such as the DSMR may have also posed a few problems. As the selfreported records relied upon participants' commitment to accurately and thoroughly document their behaviors, food intake and physical activity levels may have been under- or over-represented. The use of self-reported records may have also influenced the way participants generally behave. Participants concerned with social desirability may have recorded their food intake and exercise level in a way that reflected better adherence to diabetes management than usual. The fact that this study was conducted in an outpatient setting and that recordings of their behaviors were not stringently monitored, a disadvantage to using self-reported records, was that the diets were not controlled as it would have been in a laboratory or inpatient environment. Another limitation to this study is that responses on a self-reported record may have been influenced by the way participants felt at the time of completion. Tiredness, forgetfulness, or a lack of attention to detail may have led to further under- or overreporting of behaviors. Furthermore, the use of food records and pedometers may have increased consciousness of selfcare activities, thus interfering with the true efficacy of the CBI. Because the control group was an attention-control group and received more than the standard diabetes care, it may have served as another treatment group and limited treatment effects. A more stringent control group in future research may detect larger differences between the treatment and control groups.

A larger sample size may have also detected greater differences between the groups. The small sample size in this study may have limited the significance of findings in this study particularly due to the wide discrepancy found among the data. A larger sample size is therefore warranted in future studies.

Motivational level at the outset or throughout the study was not assessed. As the 24-hr diet recall is time-consuming and requires motivation, poor motivation may have interfered with the true effects of the CBT intervention. Also, because a stipend was awarded to all participants, results may not fully represent the general public. Participants involved in the study may have been motivated by the incentives offered.

In previous research, CBT was effective in improving adherence to self-care behaviors among individuals with type 2 diabetes (Christie \& Wilson, 2005; Foreyt \& Poston,
1999; Gonzalez et al., 2010; Lustman et al., 1998; Snoek \& Skinner, 2002; Surwit et al., 2002). Research also showed that CBT was effective in treating psychological diagnoses such as depression, anxiety, and post-traumatic stress disorder among Asian Americans and Pacific Islanders (Dai et al., 1999; Gelman et al., 2005; Voss Horrell, 2008).

Consistent with these studies, the current findings suggest CBI may play a positive role in facilitating diabetes selfmanagement among this population. Albeit changes in this study were minimal and not statistically powerful enough to reflect considerable differences in diet and exercise, results did reveal a consistent decrease in total kcals and increase in physical activity over time among the CBI group as opposed to the control group. As research has shown, diet and exercise are the cornerstones of diabetes management (Burnet et al., 2006; The Diabetes Prevention Program Research Group, 1999, 2002; Harris, Petrella, \& Leadbetter, 2003; Lindstrom et al., 2003; Pan et al., 1997) and often emphasized to encourage weight loss to prevent insulin insensitivity and diabetes-related illnesses such as heart disease and hypertension (Cox \& Gonder-Frederick, 1992; Smolin \& Grosvenor, 2003). Although many patients are told to simply lose weight, losing weight is not an easy task and several lifestyle habits are required for weight loss including eating a balanced meal, monitoring total calorie and carbohydrate intake, reducing intake of fat and processed sugars, controlling portion sizes, and increasing physical activity.

As diet and exercise are such key components in managing type 2 diabetes and the CBI used in this study had a positive impact on Asian Americans and Pacific Islanders with type 2 diabetes, our findings urge further investigation on how this CBI treatment may be improved. Incorporating motivational interviewing into the current CBI treatment and addressing factors that may have interfered with the lack of statistical significance among our results are warranted. Exploring the efficacy of other treatment approaches in this population is also warranted.

\section{Implications and Recommendations}

Until now, no study has been conducted on the efficacy of CBT in large numbers of Asian Americans and Pacific Islanders with type 2 diabetes; therefore, this study contributed new research to existing literature in a high-risk diverse population. Findings reinforce the need for more research exploring why the current treatment was ineffective and how it could be improved. Due to the variability among the data, the sample size in the current study may have been too small to reflect a true change. Thus, a larger sample size is needed to detect significant treatment effects. Also, as a result of the variability among the data, providing more training to participants completing diet and exercise records is recommended as well as conducting follow-up phone calls to clarify ambiguous recordings of food intake and physical activity level. 
As stated earlier, an attention-control group was used in this study. As participants in the control group received more than the standard diabetes care, a more stringent control group might be necessary to show successful treatment outcomes. A longer intervention period might also be essential to promote behavioral changes.

Previous studies have shown that CBT conducted over two sessions was efficacious in yielding positive treatment outcomes (Cucciare et al., 2009; Gelman et al., 2005; Gonzalez et al., 2010; Hinton et al., 2005; Inouye et al., 2001; Organista et al., 1994; Safren et al., 2009). Inouye et al. (2001) found that self-management training on stress reduction, cognitive restructuring, and coping skills conducted over a 12-week period improved the quality of life, overall mood, and coping strategies of individuals living with HIV/AIDS. Results of the current treatment after 6 weeks did not show any significant improvements suggesting that the treatment may not have been long enough. Again, some of this discussion seems peripheral to the topic of the article. It is plausible that participants in the current study may have needed more time to learn how to apply the skills learned in treatment to their daily lives. Therefore, a longer intervention phase is recommended. Follow-up booster sessions between assessment intervals are also recommended to increase the attainment and maintenance of behavioral changes.

Another recommendation for future research is to explore the role of motivation in the efficacy of CBI as well as the usefulness of including motivational interviewing in CBI. Future research is further warranted to examine the impact co-morbid and environmental factors such as depression, anxiety, post-traumatic stress disorder, physical ailments, and family/social demands may have on treatment outcomes.

Finally, it is recommended that Asian Americans and Pacific Islanders be examined separately rather than categorized into one ethnic group. Although cultural similarities exist between Asian Americans and Pacific Islanders, each group has distinct cultural differences and "represent very diverse populations in terms of ethnicity, language, culture, education, income level, English proficiency, and sociopolitical experience" (National Center for Biotechnology Information \& U.S. National Library of Medicine, 2001, p. 1). Compared with Asian Americans, Pacific Islanders have lower rates of income, education, and immigration.

According to Novotny (Novotny, Williams, Vinoya, Oshiro, \& Vogt, 2009), immigration status and level of acculturation was shown to have a positive association with body mass index. People born in the United States had 1.3 higher body mass indexes than those born in a different country. The differences of the groups including the unique ways in which they seek help and express distress indicate a need for more culturally sensitive intervention strategies. Examining Asian Americans and Pacific Islanders as distinct ethnic groups and tailoring the treatment according to each culture's values, traditions, social norms, and communication styles may be vital to enhance treatment competency and success. Despite the minor changes in diet and exercise revealed in this study, this study provides a launching ground for future research investigating the efficacy of CBI among diverse populations.

\section{Conclusion}

This study confirmed the difficulty and complexity of promoting diabetes management and sustaining healthy behavioral change. Although this study provides valuable implications in research on the changes of diet and exercise among Asian Americans and Pacific Islanders with type 2 diabetes, results were not statistically significant and imply that more research is needed to better understand how selfmanagement behaviors among this population can be improved. As the prevalence for type 2 diabetes continues to grow among these ethnic minorities, an effective treatment approach will remain pressing. Findings of this study hope to shed light on understudied ethnic populations with type 2 diabetes and urge the need for future research in this area.

\section{Acknowledgments}

We would like to acknowledge The ENHANCE Project team for their commitment to enhancing research and for their assistance in this project. Special thanks to Kirsten Connelly in compiling information and reviewing the manuscript and to our student volunteers, Dustin Lee, Jonathan Valdez, Kieko Nakayama, Kelly Lizardi, Kate Schuette, Kristina Krutz, and Yasuko Kato.

\section{Declaration of Conflicting Interests}

The author(s) declared no potential conflicts of interest with respect to the research, authorship, and/or publication of this article.

\section{Funding}

The author(s) disclosed receipt of the following financial support for the research and/or authorship of this article: This study was supported by NINR 5R01NR007883 (J.I.), and partially supported by NIH Grants U54MD007584, G12MD007601, and P20GM103466 (J.D.).

\section{References}

American Diabetes Association. (2012). Diagnosis and classification of diabetes mellitus. Diabetes Care, 35, S64-S71.

Bassett, D. R., Jr., \& John, D. (2010). Use of pedometers and accelerometers in clinical populations: Validity and reliability issues. Physical Therapy Reviews, 15, 135-142.

Beaton, G. H. (1994). Approaches to analysis of dietary data: Relationship between planned analyses and choiced methodology. American Journal of Clinical Nutrition, 59, 253-261.

Beck, J. S. (1995). Cognitive therapy: Basics and beyond. New York, NY: Guilford Press.

Beer-Borst, S., \& Amado, R. (1995). Validation of a self-administered 24-hour Recall Questionnaire used in a large-scaled dietary survey. Zeitschrift für Ernährungswissenschaft, 34, 183-189. 
Bielamowicz, M. K., Miller, W. C., Elkins, E., \& Ladewig, H. W. (1995). Monitoring behavioral changes in diabetes care with the diabetes self-management record. The Diabetes Educator, $21,426-431$.

Brooks-Harris, J. E. (2008). Integrative multitheoretical psychotherapy. Boston, MA: Houghton Mifflin.

Burnet, D. L., Elliott, L. D., Quinn, M. T., Plaut, A. J., Schwartz, M. A., \& Chin, M. H. (2006). Preventing diabetes in the clinical setting. Journal of General Internal Medicine, 21, 84-93.

Centers for Disease Control and Prevention. (2011). Chronic disease prevention and health promotion. Retrieved from http:// www.cdc.gov/chronicdisease/resources/publications/aag/ddt. htm

Centers for Disease Control and Prevention. (2013). Asian American populations. Retrieved from http://www.cdc.gov/ minorityhealth/populations/REMP/asian.html

Chen, S. W. H., \& Davenport, D. S. (2005). Cognitive-behavioral therapy with Chinese American clients: Cautions and modifications. Psychotherapy, 42, 101-110.

Chernoff, R. (2003). Geriatric nutrition: The health professional's handbook (2nd ed.). Sudbury, MA: Jones \& Bartlett.

Christie, D., \& Wilson, C. (2005). CBT in paediatric and adolescent health settings: A review of practice-based evidence. Pediatric Rehabilitation, 8, 241-247.

Cox, D. J., \& Gonder-Frederick, L. (1992). Major developments in behavioral diabetes research. Journal of Consulting and Clinical Psychology, 6, 628-638.

Cucciare, M. A., Sorrell, J. T., \& Trafton, J. A. (2009). Predicting response to cognitive-behavioral therapy in a sample of HIVpositive patients with chronic pain. Journal of Behavioral Medicine, 32, 340-348.

Dai, Y., Zhang, S., Yamamoto, J., Ao, M., Belin, T. R., Cheung, F., \& Hifumi, S. S. (1999). Cognitive behavioral therapy of minor depressive symptoms in elderly Chinese Americans: A pilot study. Community Mental Health Journal, 35, 537-542.

The Diabetes Prevention Program Research Group. (1999). The diabetes prevention program: Design and methods for a clinical trial in the prevention of type 2 diabetes. Diabetes Care, 22, 623-634.

The Diabetes Prevention Program Research Group. (2002). Reduction in the incidence of type 2 diabetes with lifestyle intervention or metformin. The New England Journal of Medicine, 346, 393-403.

Foreyt, J. P., \& Poston, W. S. C., II. (1999). The challenge of diet, exercise and lifestyle modification in the management of the obese diabetic patient. International Journal of Obesity, 23, S5-S11.

Furber, S., Monger, C., Franco, L., Mayne, D., Jones, L. A., Laws, R., et al. (2008). The effectiveness of a brief intervention using a pedometer and step-recording diary in promoting physical activity in people diagnosed with type 2 diabetes or impaired glucose tolerance. Health Promotion Journal of Australia, 19, 189-195.

Gelman, C. R., López, M., \& Foster, R. P. (2005). Evaluating the impact of a cognitive-behavioral intervention with depressed Latinas: A preliminary report. Social Work in Mental Health, 4, 1-16.

Goldfried, M. R., \& Davison, G. C. (1994). Clinical behavior therapy. New York, NY: John Wiley.
Gonzalez, J. S., McCarl, L. A., Wexler, D. D., Cagliero, E., Delahanty, L., Soper, T. D., . . . Safren, S. A. (2010). Cognitive Behavioral Therapy for Adherence and Depression (CBT-AD) in type 2 diabetes. Journal of Cognitive Psychotherapy, 24, 329-343.

Grey, M., Boland, E. A., Davidson, M., Yu, C., Sullivan-Bolyai, S., \& Tamborlane, W. V. (1998). Short-term effects of coping skills training as adjunct to intensive therapy in adolescents. Diabetes Care, 21, 902-908.

Harris, S. B., Petrella, R. J., \& Leadbetter, W. (2003). Lifestyle interventions for type 2 diabetes: Relevance for clinical practice. Canadian Family Physician, 49, 1618-1625.

Hart, S. L., \& Hart, T. A. (2010). The future of cognitive behavioral interventions within behavioral medicine. Journal of Cognitive Psychotherapy, 24, 344-353.

Hawai'i Health Data Warehouse, Hawai'i State Department of Health, \& Behavioral Risk Factor Surveillance System. (2014). Diabetes -Prevalence, for the State of Hawai' $i$, for the year(s)-2011, 2012. Retrieved from http://www.hhdw.org/ cms/index.php?page $=$ diabetes

Hinton, D. E., Chean, D., Pich, V., Safren, S. A., Hofmann, S. G., \& Pollack, M. H. (2005). A randomized controlled trial of cognitive-behavior therapy for Cambodian refugees with treatmentresistant PTSD and panic attacks: A cross-over design. Journal of Traumatic Stress, 18, 617-629.

Hoidrup, S., Andreasen, A. H., Osler, M., Pedersen, A. N., Jorgensen, L. M., Jorgensen, T., . . Heitmann, B. L. (2002). Assessment of habitual energy and macronutrient intake in adults: Comparison of a seven day food record with a dietary history interview. European Journal of Clinical Nutrition, 56, 105-113.

Inouye, J. (2004). Enhancing diabetes self-management (Researcher's Manual, Group B). Honolulu: University of Hawai'i School of Nursing and Dental Hygiene.

Inouye, J. (2005). Enhancing diabetes self-management (Researcher's Manual, Group A) (Version 7.2). Honolulu: University of Hawai'i School of Nursing and Dental Hygiene.

Inouye, J., Flannelly, L., \& Flannelly, K. J. (2001). The effectiveness of self-management training for individuals with HIV/ AIDS. The Journal of the Association of Nurses in AIDS Care: JANAC, 12, 73-84.

Jackson, K. A., Byrne, N. M., Magarey, A. M., \& Hills, A. P. (2008). Minimizing random error in dietary intakes assessed by 24-h recall, in overweight and obese adults. European Journal of Clinical Nutrition, 62, 537-543.

Lee, M. M., Whittemore, A. S., \& Lung, D. L. (1992). Reliability of recalled physical activity, cigarette smoking, and alcohol consumption. Annals of Epidemiology, 2, 705-714.

Lindstrom, J., Louheranta, A., Mannelin, M., Rastas, M., Salminen, V., Eriksson, J. G., \& Tuomilehto, J.(2003). The Finnish diabetes prevention study (DPS): Lifestyle intervention and 3-year results on diet and physical activity. Diabetes Care, 26, 32303236.

Lustman, P. J., Griffith, L. S., Freedland, K. E., Kissel, S. S., \& Clouse, R. E. (1998). Cognitive behavior therapy for depression in type 2 diabetes mellitus. A randomized, controlled trial. Annals of Internal Medicine, 129, 613-621.

Madden, J. P., Goodman, S. J., \& Guthrie, H. A. (1976). Validity of the 24 hour recall: Analysis of data obtained from elderly 
subjects. Journal of the American Dietetic Association, 68, 143-147.

Markowitz, S. M., Carper, M. M., Gonzalez, J. S., Delahanty, L. M., \& Safren, S. A. (2012). Cognitive-behavioral therapy for the treatment of depression and adherence in patients with type 1 diabetes: Pilot data and feasibility. Primary Care Companion CNS Discord. 14(2). doi:10.4088/PCC.11m01220.

Méndez, F. J., \& Beléndez, M. (1997). Effects of a behavioral intervention on treatment adherence and stress management in adolescents with IDDM. Diabetes Care, 20, 1370-1375.

National Center for Biotechnology Information \& U.S. National Library of Medicine. (2001). Chapter 5: Mental health care for Asians and Pacific Islanders. In Mental health: Culture, race, and ethnicity: A supplement to mental health: A report of the surgeon general, 1-45. Retrieved from http://www.ncbi.nlm. nih.gov/books/NBK44245/

National Institute of Diabetes and Digestive and Kidney Diseases. (2014). National diabetes statistics report: Estimates of diabetes and its burden in the United States, 2014. Retrieved from http://www.cdc.gov/diabetes/pubs/statsreport14/national-diabetes-report-web.pdf

Novotny, R., Williams, A. E., Vinoya, A. C., Oshiro, C. E. S., \& Vogt, T. M. (2009). US acculturation, food intake, and obesity among Asian-Pacific hotel workers. Journal of the American Dietetic Association, 109, 1712-1718.

The Office of Minority Health. (2014). Diabetes and Asian and Pacific Islanders. Retrieved from http://minorityhealth.hhs. gov/omh/browse. aspx ?lvl=4\&;lvlid=78

Organista, K. C., Muñoz, R. F., \& González, G. (1994). Cognitivebehavioral therapy for depression in low-income and minority medical outpatients: Description of a program and exploratory analyses. Cognitive Therapy and Research, 18, 241-259.

Pan, X. R., Li, G. W., Hu, Y. H., Wang, J. X., Yang, W. Y., An, Z. X., ... Howard, B. V. (1997). Effects of diet and exercise in preventing NIDDM in people with impaired glucose tolerance: The Da Qing IGT and diabetes study. Diabetes Care, 20, 537-544.

Pobutsky, A., Balabis, J., Nguyen, D.-H., \& Tottori, C. (2010). Hawai'i Diabetes Report 2010. Honolulu: Hawai'i State Department of Health, Chronic Disease Management and Control Branch, Diabetes Prevention and Control Program. Retrieved fromhttp://www.hawaiihealthmatters.org/javascript/ htmleditor/uploads/DOH_DiabetesReport2010_Lo.pdf

Poslusna, K., Ruprich, J., de Vries, J. H., Jakubikova, M., \& van't Veer, P. (2009). Misreporting of energy and micronutrient intake estimated by food records and 24 hour recalls, control and adjustment methods in practice. The British Journal of Nutrition, 101, 73-85.

Prochaska, J. O., Norcross, J. C., \& DiClemente, D. C. (1994). Changing for good: A revolutionary stage program for overcoming bad habits and moving your life positively forward. New York, NY: Harper Collins.

Safren, S. A., Gonzalez, J. S., Wexler, D. J., Psaros, C., Delahanty, L. M., Blashill, A. J., . . . Cagliero, E. (2014). A randomized controlled trial of cognitive behavioral therapy for adherence and depression (CBT-AD) in patients with uncontrolled type 2 diabetes. Diabetes Care, 37, 625-633.

Safren, S. A., O’Cleirigh, C., Tan, J. Y., Raminani, S. R., Reilly, L. C., Otto, M. W., \& Mayer, K. H. (2009). A randomized controlled trial of cognitive behavioral therapy for adherence and depression (CBT-AD) in HIV-infected individuals. Health Psychology, 28, 1-10.

Sawaya, A. L., Tucker, K., Tsay, R., Willett, W., Saltzman, E., Dallal, G. E., \& Roberts, S. B. (1996). Evaluation of four methods for determining energy intake in young and older women: Comparison with doubly labeled water measurements of total energy expenditure. American Journal of Clinical Nutrition, 63, 491-499.

Schroder, H., Covas, M. I., Marrugat, J., Vila, J., Pena, A., Alcantara, M., \& Masia, R. (2001). Use of a three-day estimated food record, a 72-hour recall and a Food Frequency Questionnaire for dietary assessment in a Mediterranean Spanish population. Clinical Nutrition, 20, 429-437.

Smolin, L. A., \& Grosvenor, M. B. (2003). Nutrition science and applications (4th ed.). Hoboken, NJ: John Wiley.

Snoek, F. J., \& Skinner, T. C. (2002). Psychological counselling in problematic diabetes: Does it help? Diabetic Medicine, 19, 265-273.

Sun, Y., Roth, D. L., Ritchie, C. S., Burgio, K. L., \& Locher, J. L. (2010). Reliability and predictive validity of energy intake measures from the 24-hour dietary recalls of homebound older adults. Journal of the Academy of Nutrition and Dietetics, 110, 773-778.

Surwit, R. S., van Tilburg, M. A. L., Zucker, N., McCaskill, C. C., Parekh, P., Feinglos, M. N., . . Lane, J. D. (2002). Stress management improves long-term glycemic control in type 2 diabetes. Diabetes Care, 25, 30-34.

Voss Horrell, S. C. (2008). Effectiveness of cognitive-behavioral therapy with adult ethnic minority clients: A review. Professional Psychology: Research and Practice, 39, 160-168.

Williams, M. W., Foo, K. H., \& Haarhoff, B. (2006). Cultural considerations in using cognitive behaviour therapy with Chinese people: A case study of an elderly Chinese woman with generalised anxiety disorder. New Zealand Journal of Psychology, 35, 153-162.

Wong, D. F. K., Chau, P., Kwok, A., \& Kwan, J. (2007). Cognitivebehavioral treatment groups for people with chronic physical illness in Hong Kong: Reflections on a culturally attuned model. International Journal of Group Psychotherapy, 57, 367-385.

\section{Author Biographies}

Jan Yomogida is a licensed clinical psychologist and registered dietitian in Portland, Oregon. She provides individual counseling and focuses on integrating physical and psychological components of wellbeing.

Jillian Inouye is a licensed psychologist and psychiatric/mental health nurse who serves as an associate dean for research for the Schools of Nursing and Allied Health Sciences at UNLV. Her research focuses on chronic health disparities, specifically type 2 diabetes.

Dongmei Li is an associate professor of clinical and translational research at the Clinical and Translational Science Institute and School of Medicine and Dentistry at University of Rochester Medical Center, NY.

James Davis is an associate professor and senior epidemiologist in the Biostatistics Core of the John A. Burns School of Medicine at University of Hawaii. He provides statistical support and conducts research on ethnic disparities in Hawaii. 